\title{
Laurent Botti, Nicolas Peypoch et Bernardin Solonandrasana, Économie du tourisme
}

Collection "Les Topos", Dunod, septembre 2013, 128 pages

Cécile Clergeau

\section{OpenEdition}

\section{Journals}

Édition électronique

URL : http://journals.openedition.org/tourisme/109

DOI : 10.4000/tourisme.109

ISSN : 2492-7503

\section{Éditeur}

Éditions touristiques européennes

\section{Édition imprimée}

Date de publication : 1 décembre 2013

Pagination : 84-85

ISSN : 2109-5671

\section{Référence électronique}

Cécile Clergeau, «Laurent Botti, Nicolas Peypoch et Bernardin Solonandrasana, Économie du tourisme », Mondes du Tourisme [En ligne], 8 | 2013, mis en ligne le 01 juin 2015, consulté le 22 septembre 2020. URL : http://journals.openedition.org/tourisme/109 ; DOI : https://doi.org/10.4000/tourisme.109

Ce document a été généré automatiquement le 22 septembre 2020.

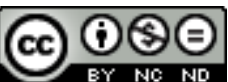

Mondes du tourisme est mis à disposition selon les termes de la licence Creative Commons Attribution - Pas d'Utilisation Commerciale - Pas de Modification 4.0 International. 


\title{
Laurent Botti, Nicolas Peypoch et Bernardin Solonandrasana, Économie du tourisme
}

\author{
Collection “Les Topos”, Dunod, septembre 2013, 128 pages
}

\section{Cécile Clergeau}

\section{RÉFÉRENCE}

Laurent Botti, Nicolas Peypoch et Bernardin Solonandrasana, Économie du tourisme, coll. "Les Topos", Dunod, 2013.

1 Ce "topo" est un petit ouvrage dont j'attendais beaucoup. Pour avoir écrit des petits livres de ce type sur la microéconomie, je sais combien il est difficile de concentrer en si peu de pages et en un si petit format tout ce que la science de l'économie recèle de trésors analytiques. Et on manque encore de livres d'économie consacrés au tourisme. Si le rédacteur en chef de la revue Mondes du tourisme a coordonné un ouvrage sur le phénomène économique qu'est le tourisme ${ }^{1}$, je peux témoigner, pour avoir participé à l'aventure, qu'aucun des auteurs n'a proposé de confronter, comme le font dans ce "topo" Laurent Botti, Nicolas Peypoch, Bernardin Solonandrasana, la théorie économique à la complexité du tourisme.

2 Je leur adresse donc, sincèrement, un grand coup de chapeau : ils ont fait le pari de chercher ce que l'économie peut nous offrir pour comprendre le tourisme. J'ai apprécié à sa juste valeur la clarté du propos, ainsi que la pédagogie des auteurs. On a finalement dans ce livre toutes les bases de la microéconomie de la firme appliquées à l'entreprise du tourisme: analyse de la firme, des coûts, des mécanismes et des structures de marché. La bibliographie nous indique les références intellectuelles des auteurs: elle marque une orientation sur l'offre et une approche extrêmement classique - plus exactement néoclassique et orthodoxe - de la firme. 
3 C'est un livre qu'on pourra recommander aux étudiants en sciences économiques, ou aux étudiants en tourisme qui souhaitent comprendre les outils de l'analyse microéconomique. À ce propos, on peut se demander pourquoi les auteurs n'ont pas affiché dans le titre cette orientation microéconomique. Microéconomie de la firme touristique aurait peut être été plus explicite.

4 Est-ce parce que j'en attendais trop? Je dois avouer avoir un peu regretté de voir certains aspects du tourisme non traités, alors même que la science de l'économie a un pouvoir explicatif sur ces phénomènes.

5 Les stratégies concurrentielles des entreprises, par exemple. Le chapitre 3 analyse la production et les coûts et finit sur une analyse des stratégies en coût. Le chapitre 4 analyse les structures de marché et précise les modes de fixation des prix. On tourne les pages pour chercher une analyse des stratégies de différenciation. Et on est un peu déçu que nos auteurs aient oublié Chamberlin et sa concurrence monopolistique.

6 Le format du livre interdit bien sûr des développements trop importants, mais des raccourcis peuvent être frustrants : on aborde ainsi la question des destinations en les présentant comme un système d'offre qui transforme des ressources en produit touristique. Et le lecteur est un peu sur sa faim car, ici encore, l'économie, et en particulier l'économie des territoires, a de quoi nourrir notre réflexion.

7 Mais finalement, ce qui m'a le plus manqué, c'est le touriste lui-même. Nos auteurs disent bien combien on peut être ennuyé par le fait de considérer le tourisme comme une industrie - le grand Alfred Marshall pourrait pourtant répondre à cette question parce qu'il n'y a pas de produit homogène, pas de système de production traditionnel. Et pourtant ils utilisent les outils analytiques néo-classiques de la production traditionnelle pour comprendre le tourisme. Mieux, ils nous disent que c'est un produit. Et là, je ne suis plus tout-à-fait d'accord. Effectivement, la production touristique n'est pas “traditionnelle" car elle n'est pas manufacturière - ce qui, soit dit en passant, n'exclut nullement l'idée d'industrie et d'industrialisation. Le tourisme, c'est d'abord du service et de la co-production. Or, l'économie est en mesure de proposer des analyses très pertinentes de la production de services. Notre confrère Jean Gadrey ${ }^{2}$, pour ne parler que de lui, a proposé il y a longtemps un cadre d'analyse très fécond de ce système de co-production. Soit, ses recherches sortent de l'orthodoxie néo-classique, mais aucun chercheur en tourisme ne peut aujourd'hui faire l'économie du concept de co-production.

8 Une analyse des flux, et de l'organisation des flux, cherche de la même façon à coller absolument aux analyses classiques de la chaîne de valeur. Pourquoi ne pas les dépasser? Les recherches de James Teboul ${ }^{3}$ sur le management des services nous montrent comment.

9 Pourquoi ne pas oser la rupture avec la microéconomie néo-classique pour comprendre toute la complexité du tourisme? L'analyse de la firme touristique (chapitre 5) reste, elle aussi, très orthodoxe et n'ouvre que très partiellement la boîte noire. Or la science de l'économie offre, avec les théories évolutionnistes, la théorie des ressources ou celle des capacités dynamiques, des outils d'une fécondité remarquable.

10 Finissant la lecture de cet ouvrage, la petite question qu'on a envie de poser à des auteurs qui ont habilement abordé la microéconomie de la firme touristique est celle de la justification d'une approche qui reste finalement classique, peut être trop. 


\section{NOTES}

1. Philippe Violier (dir.), Cécile Clergeau, Philippe Duhamel et Jean-Christophe Gay, Le Tourisme: un phénomène économique, coll. “Études”, La Documentation française, janvier 2013.

2. Jean Gadrey, L'Économie des services, La Découverte, 1992.

3. James Teboul, Le Management des services, Eyrolles-éditions d'Organisation, 2007.

\section{AUTEURS}

\section{CÉCILE CLERGEAU}

Université d'Angers 